\title{
PERSONALITY TRAITS IN SELECTION OF MILITARY, CIVIL AND SPORTS' PILOTS: HYBRIDIZED-IT2FS-MCDM APPROACH
}

\author{
Ivan Petrović ${ }^{1}$, Jelena Petrović ${ }^{2}$ \\ ${ }^{1,2}$ University of Defence, Military Academy, Belgrade, Pavla Jurisica Sturma 33, 11 000, Belgrade, Serbia
}

Received 13 May 2021; accepted 24 August 2021

\begin{abstract}
Due to its complex, time-demanding, and multifaceted structure, personnel selection is considered as a multi criteria decision-making problem, especially when it comes to the aviation. The pilot profession is highly stressful, multi-tasking, risky and expensive. This study propose an integrated methodology that leverages hybridized IT2FS-DEMATEL-AHP and fuzzy-TOPSIS methods as selection model, based on assessment personality traits of successful pilots. IT2FS-DEMATEL method is employed to eliminate non-significant traits and to obtain the weights of the importance of the final traits for the purpose of additional estimation of AHP results' consistency. IT2FS-AHP method is employed to evaluate the final traits and to calculate their weights. Fuzzy - TOPSIS method is applied to rank the candidates. Overall, 72 pilots participated in at least one measurement point of the online survey. The most important personality traits for successful commercial airplane pilots were responsible and cooperative; for military pilots determined and responsible and for sports pilots: sociable and determined.
\end{abstract}

Keywords: aviation, fuzzy-TOPSIS, human resources, IT2FS-DEMATEL-AHP method.

\section{Introduction}

The aim of selection, as one of the most vital functions of human resources management (HRM) and problem of occupational psychology is to establish the best matching between the applicants and the job description. Inaccurate selection leads to extra training, lower productivity, a rise in occupational accidents, increase in the workload of coworkers, phenomena like dropout, absenteeism, presenteeism, etc. Together with imprecise constraints, limited availability and lack of suitable candidates, and other external difficulties, like terrorist attacks, COVID - 19 pandemics, complicated laws and rules of different companies, inaccurate staff selection makes costs of flight safety (techniques, insurance costs, court costs, human lives) quite big (Čokorilo, 2008; King, 2014; Shappell et al., 2007). Mix of these potential problems, large number of criteria, along with possible conflicting objectives, tasks, roles, rules and regulations of job itself, classify selection process into multi-criteria decision-making problems (MCDM) - a process of making a selection among feasible alternatives in an attempt to attain specific objectives, and in an ideal case, it determines the best choice for the specific needs. The aim of MCDM is in accordance with environment fit theory (Barrick \& Mount, 1991) and very common used in personnel selection processes (Chen, 2000; Gibney \& Shang, 2007). Both of them emphasize importance

${ }^{2}$ Corresponding author: jelena.ilic@va.mod.gov.rs 
of KSAOs (knowledge, skills, abilities and other personality characteristics required to perform a job) in selection process. Their use is based on presumption that desirable qualities of a candidate are identified on the basis of their correlation with the qualities needed to successfully perform the job, which is of a great importance for effective crew resource management in aviation. However, Damos (1996) reports that job task analysis data (JTA), which are crucial for KSAO detection of operational pilots is difficult to find.

In terms of JTA, there are also different possible divisions between pilots according to the tasks, rules, nature of mission, requests of pilots and responsibilities. Sport pilots are flying for fun or recreation, simply because it is an interesting and challenging activity. Therefore, it seems that their tasks and duties seems to be easiest, more relaxing, have lower level of pressure, responsibility and more independence during flights, tasks and decision making process of all types of pilots. Commercial pilots' duties are mostly concerning tasks related to safely transport of people and goods. They are more likely to be cooperative since they have to rely on others crew members and in communication with colleagues and passengers. Usually they don't have such risk as military airplane pilots. Military pilots must fly their aircraft to the limits of their performance in aerial combat while simultaneously operating radar as well as offensive and defensive weapon systems.

So, the aim of this research was to identify those personality traits which are in common for all successful airplane pilots, from the perspective of experts, and to determine whether significant personality traits differences exist between pilots flying different types of mission and whether these differences could predict who will become successful commercial, sports and military pilot since matching pilots to the mission type they are best suited is for a long time goal of any flight-training program.

\section{Data and Methods}

\subsection{Sample}

Overall, 72 pilots participated in at least one measurement point of the online survey. All pilots had at least 10 years of experience on different types of airplane and their age varied from 35 to 60 , without accidents in their career. All pilots were male since there is extremely small percent of female among pilots population in Serbia generally. The members of all groups were selected so that all groups were equivalent in terms of relevant factors (absence of accidents, level of education, age of experience, etc.). In sports pilots sample only those pilots whose activity was connected with airplane flying task were included.

\subsection{Procedure}

Participation in this study was voluntarily and confidential. All examinees could give up at any time. In the first part of study, nine pilots had to nominee personality traits which they thought for important for successful pilot. After that, next 27 (nine retired military airplane pilots, commercial airplane pilots and sport airplane pilots, respectively) pilots completed DEMATEL (decision-making trial and evaluation laboratory) questionnaire about mutual influence of initial traits (27 traits). After elimination non-significant traits according to the mission, next 9 pilots were examined by using AHP (analytic hierarchy process) questionnaire, for detail evaluation of the 
final traits. After that, 27 pilots (nine retired military airplane pilots, commercial airplane pilots and sport airplane pilots, respectively) had to make self-assessment on the final personality traits for the purpose of model testing. Each participant had about 20 minutes for the first three lists, and about 10 minutes for the self - assessment list.

\subsection{Instrument}

The first instrument was the list of personality traits - nine pilots had to nominee personality traits which they thought for important for successful pilot. The respondents created list of 48 traits and only those which were chosen by all pilots were held. The second and the third instruments were DEMATEL questionnaire and AHP questionnaire developed by Saaty (1984). The fourth instrument was self assessment based on five point Likert scale from 1 = strongly disagree to $5=$ strongly agree on remained personality traits.

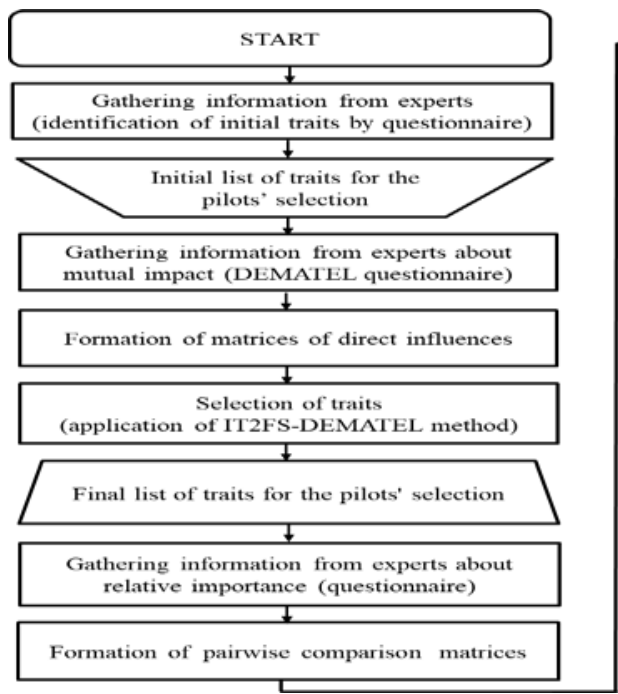

Fig. 1.

Algorithm of Research

\subsection{Variables}

Independent variables were type of pilot's mission: commercial, military and sports. Dependent variables were 27 personality traits of successful pilot (ambitious, hardworking, sociable, witty, emotional, impulsive, creative, tense, responsible, determined, careful, intelligent, permissive, obedient, righteous, practical, self - critical, self - confident, cooperative, quarrelsome, selfish, modest, patient, stubborn, persistent, efficient, brave).

\subsection{Methods and Techniques}

Research methodology in this paper based on multi-criteria decision making (MCDM) methods with interval type 2 fuzzy sets (IT2FS). The MCDM methods were often used for solving transportation material and human issues (Dožić, 2019; Pajić et al., 2021; Tadić et al., 2015). Algorithm of research was shown in Figure 1.

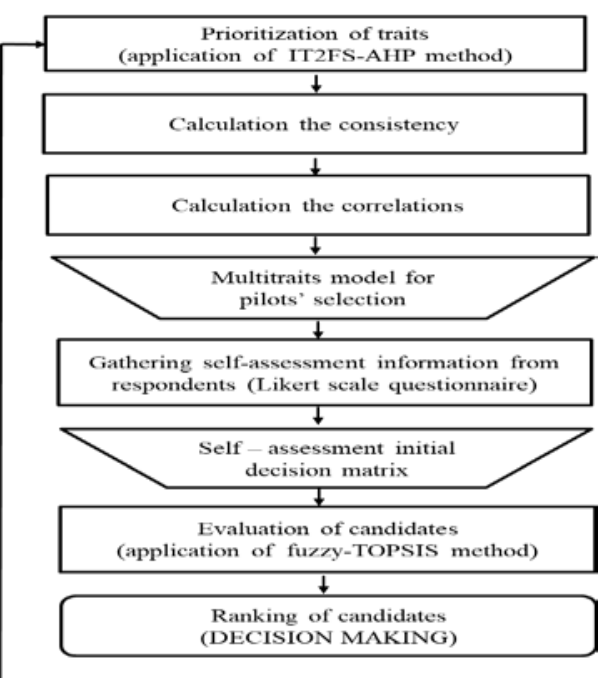




\subsection{Triangular Interval Type - 2 Fuzzy Sets}

Bearing in mind that type 1 fuzzy sets are not appropriate to model words, T2FS are developed. This type of fuzzy sets are extension of type 1 fuzzy sets, and they ensure the use of linguistic variable in conditions of linguistic uncertainty (Kahraman et al., 2014; Sari \& Kahraman, 2015; Lathamaheswari et al., 2020; Baykasoğlu \& Gölcük, 2017; Mendel, 2007). Natural extension of T2FS presents IT2FS, where the membership degree is not exact (Mendel, 2007). Unlike classical
T2FS, the IT2FS provide validity of the obtained results in conditions of high level of uncertainty of the subjective experts' opinion (Kahraman et al., 2014). In this research the triangular IT2FS were applied. The use of the triangular IT2FS, in the conditions of a large number of linguistic information ensures the reliability of the obtained results (Baykasoğlu \& Gölcük, 2017).

T2FS, in the universe of discourse $\mathrm{X}$, is presented by the following membership functions (Sari \& Kahraman, 2015; Kahraman et al., 2014):

$\widetilde{\widetilde{A}}=\left\{\left((x, u), \mu_{\widetilde{\widetilde{A}}}(x, u)\right) \mid \forall x \in X, \forall u \in J_{x} \subseteq[0,1], 0 \leq \mu_{\widetilde{\widetilde{A}}}(x, u) \leq 1\right\}$

Or,

$\widetilde{\widetilde{A}}=\iint_{x \in X, u \in J_{x}} \mu_{\widetilde{\widetilde{A}}}(x, u) /(x, u)$

Where:

$J_{x} \subseteq[0,1]$ and $\iint$ is union of all $x$ and $u$.

If $\forall \widetilde{\widetilde{A}} \Rightarrow \forall \mu_{\widetilde{\widetilde{A}}}(x, u)=1$ then T2FS $\widetilde{\widetilde{A}}$ presents IT2FS.

$\widetilde{\widetilde{A}}=\left\{((x, u), 1) \mid \forall x \in X, \forall u \in J_{x} \subseteq[0,1], \mu_{\widetilde{\widetilde{A}}}(x, u)=1\right\}$

Or:

$\widetilde{\widetilde{A}}=\iint_{x \in X, u \in J_{x}} 1 /(x, u), J_{x} \subseteq[0,1]$

The form of the triangular ITFS is (Kahraman et al. 2014):

$\widetilde{\widetilde{A}}_{i}=\left(\widetilde{A}_{i}^{U}, \widetilde{A}_{i}^{L}\right)=\left(a_{i 1}^{U}, a_{i 2}^{U}, a_{i 3}^{U} ; H\left(\widetilde{A}_{i}^{U}\right)\right),\left(a_{i 1}^{L}, a_{i 2}^{L}, a_{i 3}^{L} ; H\left(\widetilde{A}_{i}^{L}\right)\right)$

Where:

$H\left(\widetilde{A}_{i}^{U}\right)$ is the membership value of the element $a_{i 2}^{U}$ in the upper triangular function of membership, and $H\left(\widetilde{A}_{i}^{L}\right)$ is the membership value of the element $a_{i 2}^{L}$ in the lower triangular function of membership, $H\left(\widetilde{A}_{i}^{U}\right) \in[0,1], H\left(\widetilde{A}_{i}\right) \in[0,1], 1 \leq i \leq n$. 
The triangular IT2FS is graphically shown in Figure 2.

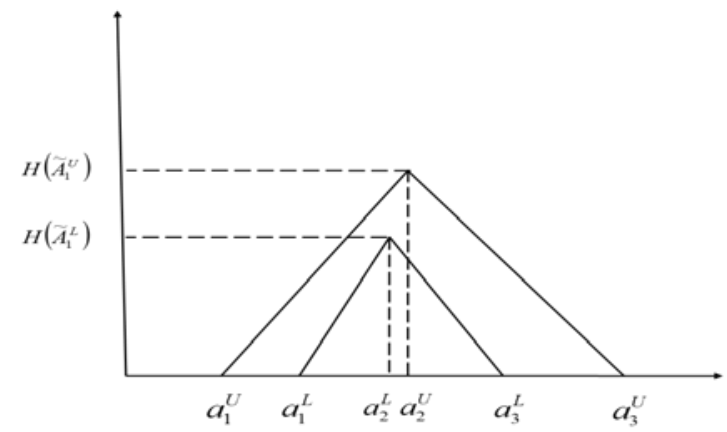

Fig. 2.

The Form of the Triangular Interval Type-2 Fuzzy Sets

Basic operations, which are valid for trapezoidal IT2FS (Sari \& Kahraman, 2015; Kahraman et al., 2014) can be presented analogously for triangular IT2FS.

For two triangular IT2FS:

$\widetilde{\widetilde{A}}_{1}=\left(\widetilde{A}_{1}^{U}, \widetilde{A}_{1}^{L}\right)=\left(a_{11}^{U}, a_{12}^{U}, a_{13}^{U} ; H\left(\widetilde{A}_{1}^{U}\right)\right),\left(a_{11}^{L}, a_{12}^{L}, a_{13}^{L} ; H\left(\widetilde{A}_{1}^{L}\right)\right)$

$\widetilde{\widetilde{A}}_{2}=\left(\widetilde{A}_{2}^{U}, \widetilde{A}_{2}^{L}\right)=\left(a_{21}^{U}, a_{22}^{U}, a_{23}^{U} ; H\left(\widetilde{A}_{2}^{U}\right)\right),\left(a_{21}^{L}, a_{22}^{L}, a_{23}^{L} ; H\left(\widetilde{A}_{2}^{L}\right)\right)$

Their elementary operations are respectively given as follows (Sari \& Kahraman, 2015):

1) The addition:

$\widetilde{\widetilde{A}}_{1} \oplus \widetilde{\widetilde{A}}_{2}=\left[a_{11}^{U}+a_{21}^{U}, a_{12}^{U}+a_{22}^{U}, a_{13}^{U}+a_{23}^{U} ; \min \left(H\left(\widetilde{A}_{1}^{U}\right)\right), \min \left(H\left(\tilde{A}_{2}^{U}\right)\right)\right]$,

$\left[a_{11}^{L}+a_{21}^{L}, a_{12}^{L}+a_{22}^{L}, a_{13}^{L}+a_{23}^{L} ; \min \left(H\left(\widetilde{A}_{1}^{L}\right)\right), \min \left(H\left(\widetilde{A}_{2}^{L}\right)\right)\right]$

2) The subtraction:

$\widetilde{\widetilde{A}}_{1}-\widetilde{\widetilde{A}}_{2}=\left[a_{11}^{U}-a_{23}^{U}, a_{12}^{U}-a_{22}^{U}, a_{13}^{U}-a_{21}^{U} ; \min \left(H\left(\widetilde{A}_{1}^{U}\right), H\left(\widetilde{A}_{2}^{U}\right)\right)\right]$,
$\left[a_{11}^{L}-a_{23}^{L}, a_{12}^{L}-a_{22}^{L}, a_{13}^{L}-a_{21}^{L} ; \min \left(H\left(\widetilde{A}_{1}^{L}\right), H\left(\widetilde{A}_{2}^{L}\right)\right)\right]$

3) The multiplication:

$\widetilde{\widetilde{A}}_{1} \otimes \widetilde{\widetilde{A}}_{2}=\left[a_{11}^{U} \times a_{21}^{U}, a_{12}^{U} \times a_{22}^{U}, a_{13}^{U} \times a_{23}^{U} ; \min \left(H\left(\widetilde{A}_{1}^{U}\right)\right), \min \left(H\left(\widetilde{A}_{2}^{U}\right)\right)\right]$, $\left[a_{11}^{L} \times a_{21}^{L}, a_{12}^{L} \times a_{22}^{L}, a_{13}^{L} \times a_{23}^{L} ; \min \left(H\left(\widetilde{A}_{1}^{L}\right)\right), \min \left(H\left(\widetilde{A}_{2}^{L}\right)\right)\right]$ 
4) The division:

$$
\begin{aligned}
& \frac{\widetilde{\widetilde{A}}_{1}}{\widetilde{\widetilde{A}}_{2}}=\left[\frac{a_{11}^{U}}{a_{23}^{U}}, \frac{a_{12}^{U}}{a_{22}^{U}}, \frac{a_{13}^{U}}{a_{21}^{U}} ; \min \left(H\left(\widetilde{A}_{1}^{U}\right), H\left(\widetilde{A}_{2}^{U}\right)\right)\right], \\
& {\left[\frac{a_{11}^{L}}{a_{23}^{L}}, \frac{a_{12}^{L}}{a_{22}^{L}}, \frac{a_{13}^{L}}{a_{21}^{L}} ; \min \left(H\left(\widetilde{A}_{1}^{L}\right), H\left(\widetilde{A}_{2}^{L}\right)\right)\right]}
\end{aligned}
$$

5) The multiplication and division operations between the triangular IT2FS and scalar $k$ :

$$
\begin{aligned}
& k \otimes \widetilde{\widetilde{A}}_{i}=k \otimes\left(\widetilde{A}_{i}^{U}, \widetilde{A}_{i}^{L}\right)=\left(k \times a_{i 1}^{U}, k \times a_{i 2}^{U}, k \times a_{i 3}^{U} ; H\left(\widetilde{A}_{i}^{U}\right)\right), \\
& \left(k \times a_{i 1}^{L}, k \times a_{i 2}^{L}, k \times a_{i 3}^{L} ; H\left(\widetilde{A}_{i}^{L}\right)\right) \\
& \frac{\widetilde{A}_{i}}{k}=\left[\frac{a_{i 1}^{U}}{k}, \frac{a_{i 2}^{U}}{k}, \frac{a_{i 3}^{U}}{k} ; H\left(\tilde{A}_{i}^{U}\right)\right],\left[\frac{a_{i 1}^{L}}{k}, \frac{a_{i 2}^{L}}{k}, \frac{a_{i 3}^{L}}{k} ; H\left(\tilde{A}_{i}^{L}\right)\right]
\end{aligned}
$$

6) The reciprocal of the triangular IT2FS:

$$
\frac{1}{\widetilde{\widetilde{A}}_{i}}=\left[\frac{1}{a_{i 3}^{U}}, \frac{1}{a_{i 2}^{U}}, \frac{1}{a_{i 1}^{U}} ; H\left(\widetilde{A}_{i}^{U}\right)\right],\left[\frac{1}{a_{i 3}^{L}}, \frac{1}{a_{i 2}^{L}}, \frac{1}{a_{i 1}^{L}} ; H\left(\widetilde{A}_{i}^{L}\right)\right]
$$

7) For any triangular IT2FS $\widetilde{\widetilde{A}}_{i}, \sqrt[m]{\widetilde{\widetilde{A}}_{i}}$ is:

$\sqrt[m]{\widetilde{\widetilde{A}}_{i}}=\left[\left(\sqrt[m]{a_{i 1}^{U}}, \sqrt[m]{a_{i 2}^{U}}, \sqrt[m]{a_{i 3}^{U}} ; H\left(\widetilde{A}_{i}^{U}\right)\right),\left(\sqrt[m]{a_{i 1}^{L}}, \sqrt[m]{a_{i 2}^{L}}, \sqrt[m]{a_{i 3}^{L}} ; H\left(\widetilde{A}_{i}^{L}\right)\right)\right]$

8) Defuzzification of the triangular IT2FS $\widetilde{\widetilde{A}}_{i}$ is (Kahraman et al. 2014):

$\operatorname{DTriTT}_{i}=\frac{1}{2}\left\{\begin{array}{l}{\left[\left(a_{i 3}^{U}-a_{i 1}^{U}\right)+\left(a_{i 2}^{U}-a_{i 1}^{U}\right)\right] / 3+a_{i 1}^{U}+} \\ \left.\left.H\left(\widetilde{A}_{i}^{L}\right) \times \llbracket\left(a_{i 3}^{L}-a_{i 1}^{L}\right)+\left(a_{i 2}^{L}-a_{i 1}^{L}\right)\right] / 3+a_{i 1}^{L}\right]\end{array}\right\}$

\subsection{Triangular ITF2S-DEMATEL Method}

The less significant initial traits were eliminated by the triangular IT2FS - DEMATEL method (Hosseini \& Tarokh, 2013). Application of this method provides researching the cause and effect relationships among criteria (in this case traits) and construction of the structural model for analyzing complex mutual relationships among criteria (Celik et al., 2015; Sangaiah et al., 2015). In addition to researching cause-effect relationship between the criteria, and determining significant and less significant criteria, this method can also be used to evaluate the criteria and calculate their weights of importance (Baykasoğlu \& Gölcük, 2017; Kilic et al., 2020). Basic strengths and weakness of this method were described by Gavade (2014).

\section{ijtte 6}


The procedure of the triangular IT2FS -DEMATEL method is as follows (Hosseini \& Tarokh, 2013):

1) The average IT2FS matrix of the influence between traits was obtained using formula 6 and 11:

$$
\tilde{\tilde{D}}=\left[\tilde{\tilde{D}}_{i j}\right]_{n \times n}=\left[\frac{\tilde{\tilde{D}}_{i j}^{(1)} \oplus \tilde{\tilde{D}}_{i j}^{(2)} \oplus \ldots \oplus \tilde{\tilde{D}}_{i j}^{(k)}}{k}\right]_{n \times n}
$$

Where is:

$\tilde{\tilde{D}}^{(k)}=\left[\tilde{\tilde{D}}_{i j}^{(k)}\right]_{n \times n}$ - individual IT2FS matrix of the influence between traits of k-th expert (after transformation linguistic variables in IT2FS),

$k$ - number of experts,

$n$ - number of final traits.

$\widetilde{\widetilde{D}}_{i j}=\left(\widetilde{D}_{i j}^{U}, \widetilde{D}_{i j}^{L}\right)=\left(d_{i j 1}^{U}, d_{i j 2}^{U}, d_{i j 3}^{U} ; H\left(\widetilde{D}_{i j}^{U}\right)\right),\left(d_{i j 1}^{L}, d_{i j 2}^{L}, d_{i j 3}^{L} ; H\left(\widetilde{D}_{i j}^{L}\right)\right)$ is the triangular IT2FS element of the non-negative average IT2FS matrix of the influence between traits.

2) If $^{s=1 / \max }\left(\sum_{1 \leqslant i s} \sum_{j=1}^{n} d_{i j 3,1<j \leqslant n}^{U} \sum_{i=1}^{n} d_{i j 3}^{U}\right)$, the normalized direct-relation matrix is (Hosseini \& Tarokh, 2013):

$\tilde{\tilde{X}}=\left[\tilde{\tilde{x}}_{i j}\right]_{n \times n}, \tilde{\tilde{x}}_{i j}=\left(\tilde{x}_{i j}^{U}, \tilde{x}_{i j}^{L}\right)=\left(x_{i j 1}^{U}, x_{i j 2}^{U}, x_{i j 3}^{U} ; H\left(\tilde{x}_{i j}^{U}\right)\right),\left(x_{i j 1}^{L}, x_{i j 2}^{L}, x_{i j 3}^{L} ; H\left(\tilde{x}_{i j}^{L}\right)\right)$ is the triangular IT2FS element of the normalized direct-relation matrix, where is:

$\tilde{\tilde{x}}_{i j}=s \otimes \tilde{\tilde{D}}_{i j}$

$H\left(\tilde{x}_{i j}^{U}\right)=H\left(\tilde{D}_{i j}^{U}\right), H\left(\tilde{x}_{i j}^{L}\right)=H\left(\tilde{D}_{i j}^{L}\right), i=1, \ldots n, j=1,2, \ldots, n$

3) The total relation matrix is:

$\tilde{\tilde{T}}=\left[\tilde{\tilde{t}}_{i j}\right]_{n \times n}, \tilde{\tilde{t}}_{i j}=\left(\tilde{t}_{i j}^{U}, \tilde{t}_{i j}^{L}\right)=\left(t_{i j 1}^{U}, t_{i j 2}^{U}, t_{i j 3}^{U} ; H\left(\tilde{t}_{i j}^{U}\right)\right),\left(t_{i j 1}^{L}, t_{i j 2}^{L}, t_{i j 3}^{L} ; H\left(\tilde{t}_{i j}^{L}\right)\right)$ - The IT2FS element of the total relation matrix, where is:

$t_{i j 1}^{U}=x_{i j 1}^{U} \times\left(i_{i j 1}^{U}-x_{i j 1}^{U}\right)^{-1}, \ldots, t_{i j 3}^{U}=x_{i j 3}^{U} \times\left(i_{i j 3}^{U}-x_{i j 3}^{U}\right)^{-1}$,

$t_{i j 1}^{L}=x_{i j 1}^{L} \times\left(i_{i j 1}^{L}-x_{i j 1}^{L}\right)^{-1}, \ldots, t_{i j 3}^{L}=x_{i j 3}^{L} \times\left(i_{i j 3}^{L}-x_{i j 3}^{L}\right)^{-1}$,

$H\left(\tilde{t}_{i j}^{U}\right)=H\left(\tilde{x}_{i j}^{U}\right), H\left(\tilde{t}_{i j}^{L}\right)=H\left(\tilde{x}_{i j}^{L}\right), i=1, \ldots n, j=1,2, \ldots, n$

$\tilde{\tilde{I}}=\left[\tilde{\tilde{i}}_{i j}\right]_{n \times n}, \tilde{\tilde{i}}_{i j}=\left(i_{i j 1}^{U}, i_{i j 2}^{U}, i_{i j 3}^{U} ; H\left(\tilde{x}_{i j}^{U}\right)\right),\left(i_{i j 1}^{L}, i_{i j 2}^{L}, i_{i j 3}^{L} ; H\left(\tilde{x}_{i j}^{L}\right)\right)$ - is the triangular IT2FS identity square matrix with elements on the main diagonal:

$\tilde{\tilde{i}}_{i j}=\left(1,1,1 ; H\left(\tilde{x}_{i j}^{U}\right)\right),\left(1,1,1 ; H\left(\tilde{x}_{i j}^{L}\right)\right), 1 \leq i \leq n, 1 \leq j \leq n, i=j$,

Other elements are:

$\tilde{\tilde{i}}_{i j}=\left(0,0,0 ; H\left(\tilde{x}_{i j}^{U}\right)\right),\left(0,0,0 ; H\left(\tilde{x}_{i j}^{L}\right)\right), 1 \leq i \leq n, 1 \leq j \leq n, i \neq j$. 
4) Using formula 14 defuzzification of the elements of the triangular IT2FS total relation matrix elements $\operatorname{DTriT}_{\tilde{T}} \widetilde{T}=T=\left[t_{i}\right]_{1 \times n}$ was obtained and threshold value was calculated (Sumrit, \& Anuntavoranich, 2013):

$\alpha=\frac{\sum_{i=1}^{n} \sum_{j=1}^{n} t_{i j}}{N}$

$\alpha$ - Threshold value,

$N=n^{2}-$ Number of the total relation matrix DTriT $\widetilde{\widetilde{T}}$ elements.

Proposed elimination of less significant traits was performed by comparing the values of $i$ -th trait in $\boldsymbol{i}$-th row (for $\mathbf{j}=\mathbf{1}, . ., \boldsymbol{n}$ ) in the total relation matrix with the threshold value, and if all values of the trait in row (values of direct effect) are equal or less than the threshold value (if $\left.\alpha \geq \max _{1 \leq j \leq n}\left(t_{i j}\right)\right), \boldsymbol{i}$ - trait was eliminated (Stević et al., 2017; Sumrit, \& Anuntavoranich, 2013).

5) From defuzzificated total relation matrix, sum of rows $D_{i}, i=1,2, \ldots, n$ (efect each trait on other traits) and sum of columns $R_{j}, j=1,2, \ldots, n$ (cause relationship - influence other traits on each trait) were calculated as follows (Baykasoğlu \& Gölcük, 2017):

$D_{i}=\sum_{j=1}^{n} t_{i j}^{d e f}$

$R_{j}=\sum_{i=1}^{n} t_{i j}^{d e f}$

6) The final traits' weights of importance are :

$\operatorname{imp}_{i}=\sqrt{\left(D_{i}+R_{i}\right)^{2}+\left(D_{i}-R_{i}\right)^{2}}$

7) The normalized final traits' weights of importance are:

$i m p W_{i}=\frac{i m p w_{i}}{\sum_{i=1}^{n} i m p w_{i}}, i=1, \ldots, n$ - number of traits

Using Spearman's rank coefficient, the correlations between rank of final traits (based on the final traits'weights obtained by applying IT2FS-AHP method) and rank of the weights of importance of final traits (obtained by applying ITFS-DEMATEL method) was found (Abdullah \& Zulkifli, 2015).

\subsection{Triangular ITF2S-AHP Method}

The weights of the final (non-eliminated) traits were calculated by using the triangular IT2FS-AHP method (Kahraman et al. 2014). This MCDM method, developed by Saaty 
(1984), ensures hierarchical decomposition of a complex MCDM problem. Using AHP method, it is possible to solve MCDM problem with ability to provide measures of consistency of preference in the conditions of subjective judgments of multiple decision makers. Basic strengths and weakness of this method were described by Gavade (2014).

The procedure of the triangular IT2FS -AHP method is as follows (Kiracı \& Akan, 2020):

1) The initial values were gathered by experts in the form of AHP adapted linguistic variables. Using formulas 6, 11 and 12 and AHP rules, the average matrix of pairwise comparisons was calculated (after transformation linguistic variables in IT2FS):

$\tilde{\tilde{A}}=\left[\tilde{\tilde{A}}_{i j}\right]_{n \times n}=\left[\frac{\tilde{\tilde{A}}_{i j}^{(1)} \oplus \tilde{\tilde{A}}_{i j}^{(2)} \oplus \ldots \oplus \tilde{\tilde{A}}_{i j}^{(k)}}{k}\right]_{n \times n}$

Where is:

$\tilde{\tilde{A}}^{(k)}=\left[\tilde{\tilde{A}}_{i j}^{(k)}\right]_{n \times n}$ - individual matrix of pairwise comparisons of k-th expert,

$\widetilde{\widetilde{A}}_{i j}=\left(a_{i j 1}^{U}, a_{i j 2}^{U}, a_{i j 3}^{U} ; H\left(\tilde{A}_{i j 1}^{U}\right)\right),\left(a_{i 1}^{L}, a_{i 2}^{L}, a_{i 3}^{L} ; H\left(\tilde{A}_{i}^{L}\right)\right), 1 \leq i \leq n, 1 \leq j \leq n$-element of the average matrix of pairwise comparisons.

For main diagonal elements: $a_{i j 1}^{U}=a_{i j 2}^{U}=a_{i j 3}^{U}=a_{i 1}^{L}=a_{i 2}^{L}=a_{i 3}^{L}=1, i=j$,

For non-main diagonal elements: $\widetilde{\widetilde{A}}_{i j}=\frac{1}{\widetilde{\widetilde{A}}_{j i}}, i \neq j$.

$n$ - Number of final traits, $k$ - number of experts (decision makers).

2) The triangular IT2FS traits' weights $\widetilde{\widetilde{w}}_{i}, i=1, \ldots, n$ were obtained as follows (using formulas 6, 8, 9 and 13):

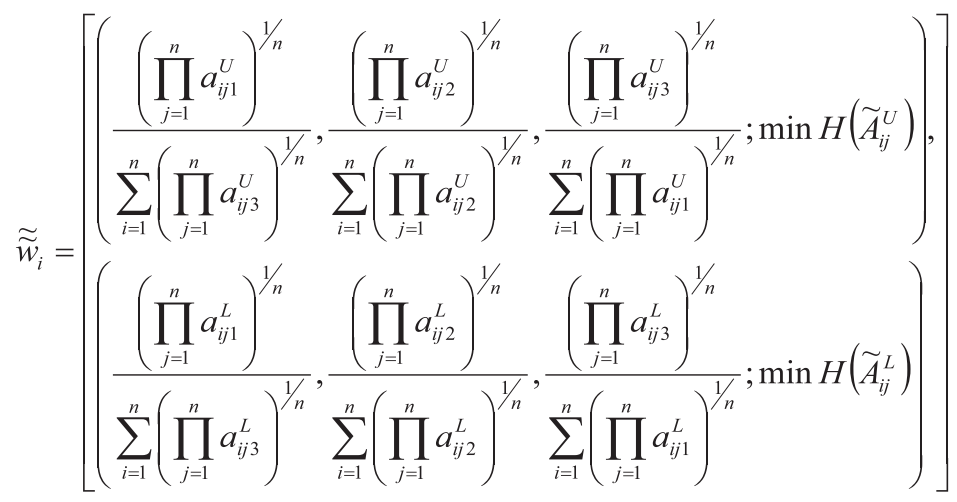


3) Using formula 14 defuzzification was performed and $D T r i T \widetilde{\widetilde{w}}_{i}, i=1, \ldots, n$ was calculated. The "crisp" values of the weights $W_{i}$ were obtained after normalization of the values of DTriT $\widetilde{\widetilde{w}}_{i}$ (Baykasoğlu \& Gölcük, 2017):

$W_{i}=\frac{D T r i T \widetilde{\widetilde{w}}_{i}}{\sum_{i=1}^{n} D \operatorname{TriT} \widetilde{\widetilde{w}}_{i}}, i=1, \ldots, n$ - number of traits

4) Procedure for checking consistency is as follows (Saaty, 1984; Buckley, 1985):

Using formula 14 defuzzification of the initial average matrix of pairwise comparisons $\tilde{\tilde{A}}=\left[\tilde{\tilde{A}}_{i j}\right]_{n \times n}$ was performed and the crisp values for calculation of the consistency ratio were obtained $A=\left[A_{i j}\right]_{n \times n}$.

The rules for calculation of consistency ratio are as follows:

$$
\begin{aligned}
& {\left[\begin{array}{l}
b_{1} \\
b_{2} \\
b_{n}
\end{array}\right]_{n \times 1}=\left[\begin{array}{l}
A_{11} A_{12} A_{1 n} \\
A_{21} A_{22} A_{2 n} \\
A_{n 1} A_{n 2} A_{n n}
\end{array}\right]_{n \times n} \times\left[\begin{array}{l}
W_{1} \\
W_{2} \\
W_{n}
\end{array}\right]_{n \times 1}, \lambda_{i}=\frac{b_{i}}{W_{i}}, \lambda_{\max }=\frac{1}{n} \times \sum_{i=1}^{n} \lambda_{i}} \\
& C I=\frac{\lambda_{\max }-n}{n-1} \\
& C R=\frac{C I}{R I}
\end{aligned}
$$

$R I$ - Random index, CI - consistency index.

$W_{i}, i=1, \ldots, n$ - Defuzzificated weights of traits. The value of consistency ratio is suitable for the application of IT2FS. Thus in this paper, if $C R \leq 0.2$ then the result is consistent (Başaran, 2012).

\subsection{FUZZY-TOPSIS Method}

The selection model was tested by using fuzzy-TOPSIS method. This method is based on the ranking of alternatives in relation to the ideal solution and negative ideal solution (Hwang and Yoon, 1981; Sangaiah et al., 2015).

The procedure of the application of TOPSIS method is as follows (Hwang and Yoon, 1981):

1) In the first step, from the information about traits and alternatives the initial decision matrix was formed. 
$\widetilde{F}=\left[\widetilde{f}_{i j}\right]_{n \times m}, 1 \leq i \leq n, 1 \leq j \leq m$

$\tilde{f}_{i j}=\left(f_{i j 1}, f_{i j 2}, f_{i j 3}\right)$, fuzzy element of the initial decision matrix,

$n$ - Number of traits,

$m$ - Number of candidates.

2) The normalized decision matrix is:

$\widetilde{R}=\left[\widetilde{r}_{i j}\right]_{n \times m}=\left[f_{i j 1} / \sqrt{\sqrt{\sum_{j=1}^{m} f_{i j 3}^{2}}}, \sqrt{i j 2} / \sqrt{\sum_{j=1}^{m} f_{i j 2}^{2}}, \quad f_{i j 3} / \sqrt{\sum_{j=1}^{m} f_{i j 1}^{2}}\right]_{n \times m} \quad 1 \leq i \leq n, 1 \leq j \leq m$

3) The weighted decision matrix is:

$\widetilde{V}=\left[\widetilde{v}_{i j}\right]_{n \times m}=\left[\left(v_{i j 1}, v_{i j 2}, v_{i j 3}\right)\right]_{n \times m}, \widetilde{v}_{i j}=W_{i} \otimes \widetilde{r}_{i j}$

4) The defuzzificated weighted normalized decision matrix (Kahraman et al., 2014):

$V_{i j}^{d e f}=\left[v_{i j}^{d e f}\right]_{n \times m}=\left[\frac{\left(v_{i j 1}+4 \times v_{i j 2}+v_{i j 3}\right)}{6}\right]_{n \times m}$

5) The positive and negative ideal solutions are respectively calculated:

$V_{j}^{+}=\left\{\left(\max v_{i j}^{\text {def }}, i \in G\right), j=1, \ldots, m\right\}=\left\{v_{1}^{\text {der }+}, v_{2}^{\text {def }+}, . ., v_{n}^{\text {def }+}\right\}$,

$V_{j}^{-}=\left\{\left(\min v_{i j}^{d e f}, i \in G\right), j=1, \ldots, m\right\}=\left\{v_{1}^{d e f-}, v_{2}^{d e f-}, . ., v_{n}^{\text {def- }}\right\}$

$G$ - The traits (all traits are of the benefit type).

6) The distance between the candidate, positive, and negative ideal solution is:

$S_{j}^{+}=\sqrt{\sum_{i=1}^{n}\left(v_{i j}^{d e f}-v_{i j}^{d e f+}\right)^{2}}, \quad 1 \leq j \leq m$
$S_{j}^{-}=\sqrt{\sum_{i=1}^{n}\left(v_{i j}^{d e f}-v_{i j}^{d e f-}\right)^{2}}, 1 \leq m$

7) The value of the relative degree of closeness to ideal solutions for each candidate is:

$Q_{j}^{*}=S_{j}^{-} /\left(S_{j}^{+}+S_{j}^{-}\right), 0 \leq Q_{j}^{*} \leq 1$

8) The candidates are ranked (the optimal solutions is the candidate that has the largest value of $Q_{j}^{*}$ ). 


\section{Results}

After transformation linguistic variables into IT2FS, significance of personality traits, elimination of less significant traits and calculation of the weights of importance of final traits was performed by using IT2FSDEMATEL method (formulas 15-22). The values of initial influence expressed by linguistic variables and IT2FS are shown in Table 1 (there is no influence of the trait on itself). Obtained results are shown in table 2.

Table 1

DEMATEL Causal Influence Linguistic Variables

\begin{tabular}{|l|l|}
\hline Linguistic Variable of Influence & Triangular IT2FS \\
\hline No $(\mathrm{N})$ & $((0,0,0 ; 1),(0,0,0 ; 0.8))$ \\
\hline Low $(\mathrm{L})$ & $((0,0.2,0.4 ; 1),(0,0.1,0.3 ; 0.8))$ \\
\hline Medium $(\mathrm{M})$ & $((0.2,0.4,0.6 ; 1),(0.1,0.3,0.5 ; 0.8))$ \\
\hline High $(\mathrm{H})$ & $((0.4,0.6,0.8 ; 1),(0.3,0.5,0.7 ; 0.8))$ \\
\hline Very High $(\mathrm{VH})$ & $((0.6,0.8,1 ; 1),(0.5,0.7,0.9 ; 0.8))$ \\
\hline
\end{tabular}

Table 2

DEMATEL Matrix

\begin{tabular}{|c|c|c|c|c|c|c|c|c|c|c|c|c|c|c|c|c|}
\hline \multirow{2}{*}{\multicolumn{2}{|c|}{ Traits }} & \multirow{2}{*}{\multicolumn{5}{|c|}{ Commercial }} & \multirow{2}{*}{\multicolumn{5}{|c|}{ Military }} & \multirow{2}{*}{\multicolumn{5}{|c|}{ Sports }} \\
\hline & & & & & & & & & & & & & & & & \\
\hline 1 & ambitious & \begin{tabular}{|c|}
$\max _{1 \leq j \leq n}\left(t_{i j}\right)$ \\
0.070 \\
\end{tabular} & \begin{tabular}{|c|}
$D_{i}+R_{i}$ \\
1.831 \\
\end{tabular} & \begin{tabular}{|c|}
$D_{i}-R_{i}$ \\
-0.198 \\
\end{tabular} & \begin{tabular}{|l|}
$i m p W_{i}$ \\
0.027 \\
\end{tabular} & $\frac{\text { Rank }}{16}$ & \begin{tabular}{|c|}
$\max _{1 \leq j \leq n}\left(t_{i j}\right)$ \\
0.137 \\
\end{tabular} & \begin{tabular}{|r|}
$D_{i}+R_{i}$ \\
1.284 \\
\end{tabular} & \begin{tabular}{|c|}
$D_{i}-R_{i}$ \\
0.229 \\
\end{tabular} & \begin{tabular}{|c|}
$i m p W_{i}$ \\
0.044 \\
\end{tabular} & $\frac{\text { Rank }}{14}$ & \begin{tabular}{|c|}
$\max _{1 \leq j \leq n}\left(t_{i j}\right)$ \\
0.162 \\
\end{tabular} & \begin{tabular}{|c|}
$D_{i}+R_{i}$ \\
4.465 \\
\end{tabular} & \begin{tabular}{|l|}
$D_{i}-R_{i}$ \\
0.065 \\
\end{tabular} & \begin{tabular}{|l} 
imp $W_{i}$ \\
0.030 \\
\end{tabular} & $\begin{array}{r}\text { Rank } \\
18 \\
\end{array}$ \\
\hline 2 & hardworking & 0.216 & 5.221 & 0.074 & 0.077 & 4 & 0.087 & 1.485 & -0.225 & 0.060 & 9 & 0.282 & 7.736 & 0.348 & 0.052 & 13 \\
\hline 3 & sociable $^{\mathrm{m}}$ & 0.144 & 2.655 & 0.407 & 0.040 & 14 & 0.018 & 0.618 & -0.691 & I & / & 0.312 & 10.386 & 0.650 & 0.070 & 1 \\
\hline 4 & witty $^{c, m}$ & 0.044 & 1.213 & -0.626 & 1 & 1 & 0.017 & 0.559 & -0.684 & 1 & 1 & 0.276 & 7.282 & 0.278 & .049 & 15 \\
\hline 5 & emotional ${ }^{\mathrm{c}, \mathrm{m}, \mathrm{s}}$ & 0.022 & 0.750 & -0.330 & 1 & 1 & 0.016 & 0.400 & -0.407 & 1 & 1 & 0.034 & 2.126 & -0.834 & 1 & 1 \\
\hline 6 & impulsive $^{\mathrm{c}, \mathrm{m}, \mathrm{s}}$ & 0.033 & 0.575 & -0.363 & I & / & 0.017 & 0.428 & -0.422 & 1 & 1 & 0.028 & 0.967 & -0.190 & / & 1 \\
\hline 7 & creative $^{c, s}$ & 0.044 & 0.616 & -0.250 & l & I & 0.135 & 1.236 & 0.106 & 0.044 & 13 & 0.090 & 3.470 & -0.280 & 1 & 1 \\
\hline 8 & tense ${ }^{c, m, s}$ & 0.016 & 0.347 & -0.241 & / & / & 0.014 & 0.298 & -0.398 & I & 1 & 0.029 & 0.960 & -0.131 & 1 & I \\
\hline 9 & responsible & 0.251 & 6.484 & 0.532 & 0.096 & 2 & 0.166 & 2.693 & 1.535 & 0.077 & 4 & 0.303 & 9.988 & 0.161 & 0.068 & 3 \\
\hline 10 & determined & 0.235 & 5.062 & 0.084 & 0.075 & 5 & 0.166 & 2.712 & 1.420 & 0.079 & 2 & 0.309 & 10.314 & 0.526 & 0.070 & 2 \\
\hline 11 & careful & 0.225 & 4.212 & 0.114 & 0.062 & 8 & 0.140 & 1.439 & 0.176 & 0.051 & 10 & 0.274 & 8.452 & -1.189 & 0.058 & 7 \\
\hline 12 & intelligent & 0.144 & 2.389 & 0.196 & 0.035 & 15 & 0.152 & 2.021 & 0.459 & 0.068 & 7 & 0.263 & 6.632 & -0.257 & 0.045 & 16 \\
\hline 13 & permissive ${ }^{c, m, s}$ & 0.016 & 0.582 & -0.443 & I & I & 0.016 & 0.477 & -0.891 & / & 1 & 0.033 & 1.362 & -0.195 & 1 & 1 \\
\hline 14 & obedient $^{\mathrm{m}}$ & 0.225 & 3.586 & 0.871 & 0.054 & 9 & 0.016 & 0.403 & -0.575 & 1 & 1 & 0.279 & 7.896 & -0.127 & 0.053 & 12 \\
\hline 15 & righteous & 0.193 & 2.899 & 0.368 & 0.043 & 12 & 0.142 & 1.608 & -0.014 & 0.061 & 8 & 0.276 & 7.308 & 0.405 & 0.050 & 14 \\
\hline 16 & practical & 0.232 & 4.476 & 0.260 & 0.066 & 7 & 0.153 & 2.119 & 0.361 & 0.073 & 6 & 0.290 & 9.083 & -0.272 & 0.061 & 6 \\
\hline 17 & self - critical & 0.200 & 3.611 & 0.048 & 0.053 & 11 & 0.157 & 2.344 & 0.571 & 0.078 & 3 & 0.301 & 9.875 & 0.050 & 0.067 & 4 \\
\hline 18 & self - confident & 0.138 & 2.818 & 0.353 & 0.042 & 13 & 0.149 & 2.052 & 0.070 & 0.076 & 5 & 0.290 & 8.164 & 0.675 & 0.055 & 10 \\
\hline 19 & cooperative & 0.263 & 6.546 & 0.480 & 0.097 & 1 & 0.084 & 1.247 & -0.082 & 0.048 & 12 & 0.294 & 9.429 & -0.176 & 0.064 & 5 \\
\hline 20 & quarrelsome $\mathrm{e}^{\mathrm{c}, \mathrm{m}, \mathrm{s}}$ & 0.017 & 0.337 & -0.210 & / & / & 0.016 & 0.428 & -0.457 & / & I & 0.032 & 1.324 & -0.247 & / & I \\
\hline 21 & selfish $^{\mathrm{c}, \mathrm{m}, \mathrm{s}}$ & 0.043 & 0.382 & -0.189 & 1 & I & 0.014 & 0.265 & -0.321 & 1 & 1 & 0.030 & 0.754 & 0.169 & 1 & 1 \\
\hline 22 & modest ${ }^{c, m, s}$ & 0.019 & 0.739 & -0.500 & 1 & / & 0.013 & 0.305 & -0.623 & 1 & 1 & 0.034 & 2.259 & -1.035 & 1 & 1 \\
\hline 23 & patient & 0.245 & 5.325 & -0.218 & 0.079 & 3 & 0.087 & 1.240 & 0.321 & 0.041 & 15 & 0.288 & 8.032 & 0.670 & 0.055 & 11 \\
\hline 24 & stubborn $^{\mathrm{c}, \mathrm{m}, \mathrm{s}}$ & 0.016 & 0.366 & -0.235 & I & I & 0.015 & 0.371 & -0.590 & 1 & I & 0.034 & 1.530 & -0.237 & 1 & 1 \\
\hline 25 & persistent & 0.247 & 4.893 & 0.490 & 0.073 & 6 & 0.424 & 2.390 & 0.576 & 0.080 & 1 & 0.283 & 8.485 & -0.264 & 0.057 & 8 \\
\hline 26 & efficient & 0.225 & 3.690 & -0.016 & 0.054 & 10 & 0.145 & 1.519 & 0.493 & 0.049 & 11 & 0.287 & 8.214 & 0.345 & 0.056 & 9 \\
\hline 27 & brave & 0.176 & 1.779 & -0.458 & 0.027 & 17 & 0.148 & 1.924 & 0.063 & 0.071 & 16 & 0.266 & 5.726 & 1.091 & 0.039 & 17 \\
\hline & $\begin{array}{l}\text { iteria of } \\
\text { mination }\end{array}$ & & $\operatorname{ax}_{i n}\left(t_{i j}\right.$ & & & & & & & & & & & & & \\
\hline
\end{tabular}

$c, m, s$ - eliminated traits according to the mission type 
By comparing the values of each trait with the threshold value, 10 less significant traits were eliminated for commercial, 11 for military pilots and nine for sports. Very high difference between the significance of eliminated and non-eliminated (final) traits can be noted in Figure 3, where are shown the values of prominence $D_{i}+R_{i}$ and relation $D_{i}-R_{i}$ for eliminated and non-eliminated traits. It is interesting to note that 12 of 27 traits were eliminated by at least one group. In common eliminated traits were emotional, impulsive, tense, permissive, quarrelsome, selfish, modest and stubborn. On the other hand, only military pilots didn't declare sociable and obedient as relevant traits for successful military pilot but they were only group that noted importance of creativity as an important trait. Commercial and military pilots ought not to be witty which is recommended for successful sports pilot.

Prioritization of final traits was performed by using the triangular IT2FS-AHP method (formulas 23-25). The linguistic variables and the triangular IT2FS-AHP pairwise comparisons of traits values are shown in Table 3.

\section{Table 3}

AHP Linguistic Variables of Traits Pairwise Comparison

\begin{tabular}{|l|l|}
\hline $\begin{array}{l}\text { Linguistic Variables of } \\
\text { Pairwise Comparison }\end{array}$ & Trapezoidal IT2FS \\
\hline Absolutely Strong (AS) & $((7,8,9 ; 1),(6,7,8 ; 0.8))$ \\
\hline Very Strong (VS) & $((5,6,7 ; 1),(4,5,6 ; 0.8))$ \\
\hline Fairly Strong (FS) & $((3,4,5 ; 1),(2,3,4 ; 0.8))$ \\
\hline Slightly Strong (SS) & $((2,3,4 ; 1),(1,2,3 ; 0.8))$ \\
\hline Equal (E) & $((1,1,1 ; 1),(1,1,1 ; 0.8))$ \\
\hline Slightly Weak (SW) & $((0.25,0.33,0.5 ; 1),(0.33,0.5,1 ; 0.8))$ \\
\hline Fairly Weak (FW) & $((0.2,0.25,0.33 ; 1),(0.25,0.33,0.5 ; 0.8))$ \\
\hline Very Weak (VW) & $((0.143,0.167,0.2 ; 1),(0.167,0.2,0.25 ; 0.8))$ \\
\hline Absolutely Weak (AW) & $((0.111,0.125,0.143 ; 1),(0.125,0.143,0.167 ; 0.8))$ \\
\hline
\end{tabular}

The consistency ratio was checked using formulas 26-28. All results are consistent. High value of Spearman's rank correlations coefficients ensures the validity of the results (Table 4). 

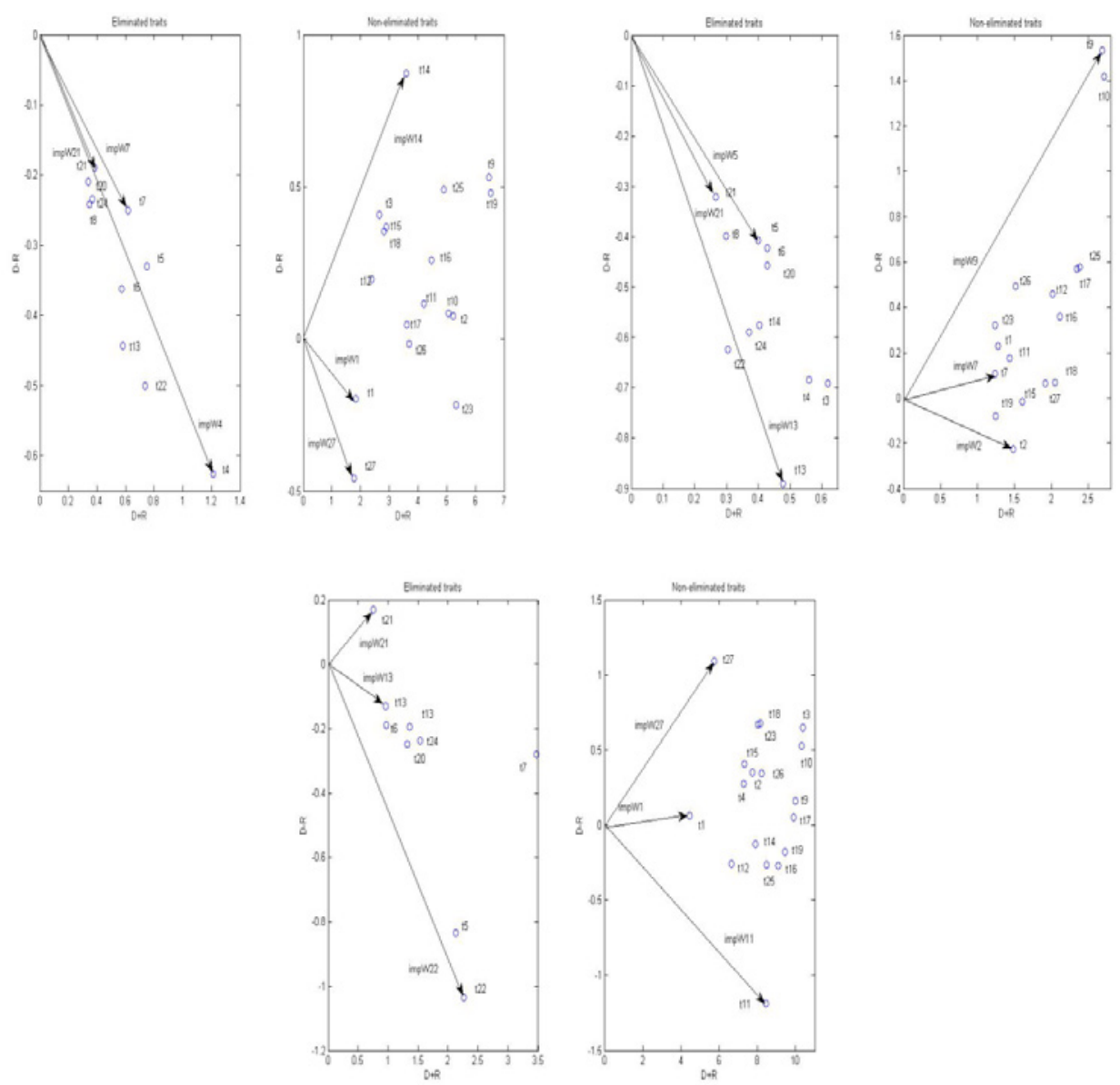

Fig. 3.

Causal Diagram for Commercial, Military and Sports Pilots and Example of Traits' Weights of Importance

The selection model was tested by using fuzzy-TOPSIS method. The initial decision matrix was formed by using individual $k(k=9)$ decision vectors based on five point Likert scale. 


\section{Table 4}

The Final Traits' Weights

\begin{tabular}{|c|c|c|c|c|c|c|c|c|c|c|c|c|}
\hline & \multicolumn{4}{|c|}{ Commercial } & \multicolumn{4}{|c|}{ Military } & \multicolumn{4}{|c|}{ Sports } \\
\hline Rank & Trait & $\widetilde{\widetilde{w}}_{i}$ & $D T r i T \widetilde{\widetilde{w}}_{i}$ & $W_{i}$ & Trait & $\widetilde{\widetilde{w}}_{i}$ & $D T r i T \widetilde{\widetilde{w}}$ & $W_{i}$ & Trait & $\widetilde{\widetilde{w}}_{i}$ & $\left|D T r i T \widetilde{\widetilde{w}}_{i}\right|$ & $W_{i}$ \\
\hline 1 & 9 & \begin{tabular}{|c|}
$(0.075,0.123,0.196 ; 1)$ \\
$(0.051,0.108,0.206 ; 0.8)$
\end{tabular} & 0.114 & 0.114 & 10 & \begin{tabular}{|c|} 
\\
$(0.098,0.161,0.253 ; 1)$ \\
$(0.062,0.135,0.260 ; 0.8)$
\end{tabular} & 0.146 & 0.146 & 3 & \begin{tabular}{|l|}
$(0.072,0.129,0.214 ; 1)$, \\
$(0.041,0.102,0.217 ; 0.8)$
\end{tabular} & 0.117 & 0.114 \\
\hline 2 & 19 & $\begin{array}{l}(0.070,0.112,0.176 ; 1) \\
(0.049,0.101,0.191 ; 0.8)\end{array}$ & 0.105 & 0.105 & 9 & $\begin{array}{l}(0.082,0.126,0.188 ; 1) \\
(0.058,0.112,0.202 ; 0.8)\end{array}$ & 0.116 & 0.115 & 10 & \begin{tabular}{|}
$(0.069,0.116,0.187 ; 1)$ \\
$(0.042,0.097,0.196 ; 0.8)$
\end{tabular} & 0.107 & 0.104 \\
\hline 3 & 2 & $\begin{array}{c}(0.060,0.096,0.153 ; 1) \\
(0.043,0.089,0.171 ; 0.8)\end{array}$ & 0.092 & 0.092 & 16 & $\begin{array}{c}(0.067,0.108,0.168 ; 1) \\
(0.046,0.096,0.185 ; 0.8)\end{array}$ & 0.101 & 0.100 & 9 & \begin{tabular}{|l|}
$(0.057,0.097,0.159 ; 1)$ \\
$0.035,0.084,0.175 ; 0.8)$ \\
\end{tabular} & 0.091 & 0.089 \\
\hline 4 & 25 & $\begin{array}{l}(0.056,0.090,0.142 ; 1) \\
(0.041,0.083,0.160 ; 0.8)\end{array}$ & 0.086 & 0.086 & 17 & \begin{tabular}{|l|}
$(0.059,0.095,0.148 ; 1)$ \\
$(0.040,0.085,0.164 ; 0.8)$ \\
\end{tabular} & 0.089 & 0.089 & 17 & \begin{tabular}{|l|}
$(0.055,0.092,0.147 ; 1)$ \\
$(0.035,0.080,0.164 ; 0.8)$ \\
\end{tabular} & 0.086 & 0.084 \\
\hline 5 & 23 & \begin{tabular}{|c|}
$(0.053,0.087,0.138 ; 1)$ \\
$(0.037,0.078,0.152 ; 0.8)$ \\
\end{tabular} & 0.082 & 0.082 & 25 & $\begin{array}{c}(0.054,0.079,0.115 ; 1) \\
(0.042,0.077,0.136 ; 0.8) \\
\end{array}$ & 0.075 & 0.075 & 19 & $\begin{array}{c}(0.052,0.088,0.145 ; 1) \\
(0.035,0.080,0.168 ; 0.8) \\
\end{array}$ & 0.085 & 0.083 \\
\hline 6 & 10 & $\begin{array}{c}(0.049,0.077,0.119 ; 1) \\
(0.038,0.073,0.136 ; 0.8)\end{array}$ & 0.074 & 0.074 & 18 & $\begin{array}{c}(0.041,0.066,0.107 ; 1) \\
(0.031,0.067,0.140 ; 0.8)\end{array}$ & 0.068 & 0.067 & 16 & $\begin{array}{c}(0.039,0.066,0.111 ; 1) \\
(0.028,0.065,0.143 ; 0.8)\end{array}$ & 0.068 & 0.066 \\
\hline 7 & 16 & $\begin{array}{l}(0.040,0.061,0.095 ; 1) \\
(0.032,0.062,0.119 ; 0.8)\end{array}$ & 0.061 & 0.061 & 27 & \begin{tabular}{|l|}
$(0.044,0.067,0.104 ; 1)$ \\
$(0.035,0.068,0.134 ; 0.8)$ \\
\end{tabular} & 0.068 & 0.067 & 25 & \begin{tabular}{|l|}
$(0.039,0.066,0.111 ; 1)$ \\
$(0.028,0.065,0.143 ; 0.8)$ \\
\end{tabular} & 0.068 & 0.066 \\
\hline 8 & 14 & $\begin{array}{c}(0.035,0.054,0.085 ; 1) \\
(0.030,0.057,0.112 ; 0.8) \\
\end{array}$ & 0.056 & 0.056 & 12 & $\begin{array}{c}(0.040,0.063,0.100 ; 1) \\
(0.033,0.066,0.134 ; 0.8) \\
\end{array}$ & 0.065 & 0.064 & 11 & $\begin{array}{c}(0.035,0.056,0.093 ; 1) \\
(0.028,0.059,0.129 ; 0.8) \\
\end{array}$ & 0.059 & 0.058 \\
\hline 9 & 26 & $\begin{array}{l}(0.034,0.050,0.076 ; 1) \\
(0.029,0.053,0.097 ; 0.8)\end{array}$ & 0.050 & 0.050 & 15 & $\begin{array}{l}(0.032,0.051,0.084 ; 1) \\
(0.028,0.058,0.125 ; 0.8) \\
\end{array}$ & 0.056 & 0.056 & 14 & \begin{tabular}{|l|}
$(0.025,0.040,0.067 ; 1)$ \\
$(0.023,0.047,0.104 ; 0.8)$ \\
\end{tabular} & 0.045 & 0.044 \\
\hline 10 & 11 & $\begin{array}{c}(0.029,0.043,0.067 ; 1) \\
(0.026,0.048,0.095 ; 0.8)\end{array}$ & 0.046 & 0.046 & 2 & $\begin{array}{c}(0.028,0.045,0.075 ; 1) \\
(0.024,0.051,0.112 ; 0.8)\end{array}$ & 0.050 & 0.050 & 18 & $\begin{array}{l}(0.024,0.038,0.065 ; 1) \\
(0.022,0.046,0.106 ; 0.8)\end{array}$ & 0.044 & 0.043 \\
\hline 11 & 3 & \begin{tabular}{|c|}
$(0.024,0.038,0.059 ; 1)$ \\
$(0.023,0.043,0.091 ; 0.8)$
\end{tabular} & 0.041 & 0.041 & 11 & $\begin{array}{c}(0.020,0.031,0.051 ; 1) \\
(0.020,0.039,0.086 ; 0.8) \\
\end{array}$ & 0.036 & 0.036 & 23 & $\begin{array}{c}(0.023,0.038,0.064 ; 1) \\
(0.021,0.045,0.104 ; 0.8) \\
\end{array}$ & 0.044 & 0.042 \\
\hline 12 & 17 & $\begin{array}{l}(0.023,0.036,0.059 ; 1) \\
(0.022,0.043,0.089 ; 0.8) \\
\end{array}$ & 0.040 & 0.040 & 26 & \begin{tabular}{|l|}
$(0.017,0.027,0.048 ; 1)$ \\
$(0.018,0.037,0.090 ; 0.8)$ \\
\end{tabular} & 0.035 & 0.035 & 26 & \begin{tabular}{|l|}
$(0.024,0.038,0.062 ; 1)$ \\
$(0.023,0.045,0.098 ; 0.8)$ \\
\end{tabular} & 0.043 & 0.041 \\
\hline 13 & 1 & $\begin{array}{c}(0.021,0.035,0.051 ; 1) \\
(0.020,0.037,0.076 ; 0.8)\end{array}$ & 0.035 & 0.035 & 1 & $\begin{array}{c}(0.018,0.028,0.046 ; 1) \\
(0.018,0.035,0.079 ; 0.8)\end{array}$ & 0.033 & 0.033 & 3 & $\begin{array}{c}(0.021,0.031,0.051 ; 1) \\
(0.021,0.040,0.087 ; 0.8)\end{array}$ & 0.037 & 0.036 \\
\hline 14 & 18 & $\begin{array}{l}(0.020,0.033,0.053 ; 1) \\
(0.018,0.036,0.078 ; 0.8) \\
\end{array}$ & 0.035 & 0.035 & 23 & $\begin{array}{l}(0.012,0.019,0.033 ; 1) \\
(0.014,0.028,0.066 ; 0.8) \\
\end{array}$ & 0.025 & 0.025 & 4 & \begin{tabular}{|l|}
$(0.017,0.026,0.045 ; 1)$ \\
$(0.018,0.036,0.087 ; 0.8)$ \\
\end{tabular} & 0.033 & 0.032 \\
\hline 15 & 15 & $\begin{array}{c}(0.018,0.027,0.044 ; 1) \\
(0.019,0.035,0.075 ; 0.8) \\
\end{array}$ & 0.032 & 0.032 & 7 & $\begin{array}{c}(0.012,0.018,0.031 ; 1) \\
(0.014,0.026,0.060 ; 0.8)\end{array}$ & 0.024 & 0.024 & 12 & $\begin{array}{c}(0.015,0.024,0.043 ; 1) \\
(0.016,0.033,0.083 ; 0.8) \\
\end{array}$ & 0.031 & 0.030 \\
\hline 16 & 12 & $\begin{array}{l}(0.014,0.020,0.033 ; 1) \\
(0.016,0.028,0.063 ; 0.8) \\
\end{array}$ & 0.026 & 0.026 & 19 & $\begin{array}{l}(0.009,0.014,0.024 ; 1) \\
(0.011,0.021,0.048 ; 0.8) \\
\end{array}$ & 0.019 & 0.018 & 15 & \begin{tabular}{|l|}
$(0.015,0.024,0.042 ; 1)$ \\
$(0.016,0.033,0.080 ; 0.8)$ \\
\end{tabular} & 0.031 & 0.030 \\
\hline 17 & 27 & $\begin{array}{c}(0.014,0.020,0.032 ; 1) \\
(0.016,0.027,0.059 ; 0.8)\end{array}$ & 0.024 & 0.024 & & & & & 27 & $\begin{array}{c}(0.010,0.016,0.030 ; 1) \\
(0.012,0.025,0.065 ; 0.8)\end{array}$ & 0.023 & 0.022 \\
\hline 18 & & & & & & & & & 1 & $\begin{array}{c}(0.008,0.014,0.024 ; 1), \\
(0.010,0.021,0.052 ; 0.8)\end{array}$ & 0.019 & 0.018 \\
\hline & $C$ & $=0.157, R I=1$ & $r=0$. & .941 & $C R$ & $=0.0705, R I=1$ & $r=0$ & 26 & & $=0.0777, R I=$ & $2, r=0$ & 0.97 \\
\hline
\end{tabular}

Traits: 1 - ambitious, 2 - hardworking, 3 - sociable, 4 - witty, 7 - creative, 9 - responsible, 10 - determined, 11 - careful, 12 - intelligent, 14 - obedient, 15 - righteous, 16 - practical, 17 - self - critical, 18 - self - confident, 19 - cooperative, 23 - patient, 25 - persistent, 26 - efficient, 27 - brave

After transformation five point Likert scale into fuzzy sets, rank of candidates was obtained by using formulas 29-34 (Table 5). 


\section{Table 5}

The Defuzzificated Weighted Decision Matrix $V_{i j}$ for Selecting Commercial, Military and Sports Pilots and Rank of Candidates (Ordered by the Most Significant Positive Trait of the Best Candidate)

\begin{tabular}{|c|c|c|c|c|c|c|c|c|c|c|c|c|c|c|c|}
\hline \multirow[t]{2}{*}{ Rank } & \multicolumn{5}{|l|}{ Commercial } & \multicolumn{5}{|l|}{ Military } & \multicolumn{5}{|l|}{ Sports } \\
\hline & Traits & 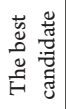 & 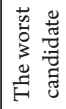 & $V_{j}^{+}$ & $V_{j}^{-}$ & Traits & 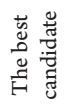 & 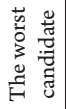 & $V_{j}^{+}$ & $V_{j}^{-}$ & Traits & 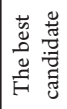 & 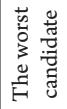 & $V_{j}^{+}$ & $V_{j}^{-}$ \\
\hline 1 & cooperative & 0.042 & 0.012 & 0.042 & 0.012 & determined & 0.053 & 0.042 & 0.053 & 0.042 & sociable & 0.052 & 0.015 & 0.052 & 0.015 \\
\hline 2 & responsible & 0.041 & 0.032 & 0.041 & 0.032 & responsible & 0.041 & 0.033 & 0.041 & 0.033 & determined & 0.038 & 0.038 & 0.038 & 0.030 \\
\hline 3 & patient & 0.035 & 0.028 & 0.035 & 0.010 & practical & 0.035 & 0.028 & 0.035 & 0.028 & cooperative & 0.033 & 0.009 & 0.033 & 0.009 \\
\hline 4 & hardw & 0.034 & 0.027 & 0.034 & 0.027 & self-critical & 0.032 & 0.026 & 0.032 & 0.026 & responsible & 0.031 & 0.025 & 0.031 & 0.025 \\
\hline 5 & persistent & 0.031 & 0.031 & 0.031 & 0.024 & $\begin{array}{c}\text { self - } \\
\text { confident }\end{array}$ & 0.028 & 0.022 & 0.028 & 0.015 & self - critical & 0.031 & 0.031 & 0.031 & 0.024 \\
\hline 6 & obedient & 0.028 & 0.015 & 0.028 & 0 & brave & 0.025 & 0.020 & 0.025 & 0.020 & careful & 0.023 & 0.023 & 0.023 & 0.018 \\
\hline 7 & determined & 0.027 & 0.027 & 0.027 & 0.021 & intelligent & 0.024 & 0.019 & 0.024 & 0.019 & practical & 0.023 & 0.023 & 0.023 & 0.018 \\
\hline 8 & practical & 0.021 & 0.021 & 0.021 & 0.017 & persistent & 0.021 & 0.021 & 0.027 & 0.021 & persistent & 0.023 & 0.023 & 0.023 & 0.019 \\
\hline 9 & sociable & 0.019 & 0.006 & \begin{tabular}{|l|}
0.019 \\
\end{tabular} & 0 & righteous & 0.020 & 0.016 & 0.020 & \begin{tabular}{|l|}
0.016 \\
\end{tabular} & obedient & 0.022 & \begin{tabular}{|l|}
0.012 \\
\end{tabular} & 0.022 & 0 \\
\hline 10 & careful & 0.018 & 0.018 & 0.018 & 0.015 & hardworking & 0.019 & 0.015 & 0.019 & 0.015 & patient & 0.018 & 0.014 & 0.018 & 0.005 \\
\hline 11 & efficient & 0.018 & 0.022 & 0.022 & 0.012 & efficient & 0.015 & 0.008 & 0.015 & 0.008 & hardworking & 0.014 & 0.012 & 0.014 & 0 \\
\hline 12 & ambit & 0.015 & 0.015 & 0.015 & 0.004 & ambitious & 0.014 & 0.011 & 0.014 & 0.004 & $\begin{array}{c}\text { self - } \\
\text { confident }\end{array}$ & 0.014 & 0.018 & 0.018 & 0.010 \\
\hline 13 & self - critical & 0.015 & 0.015 & 0.015 & 0.012 & careful & 0.014 & 0.012 & 0.014 & 0.012 & efficient & 0.014 & 0.018 & 0.018 & 0.010 \\
\hline 14 & righteous & 0.012 & 0.009 & 0.012 & 0.009 & creative & 0.011 & 0.009 & 0.011 & 0.006 & witty & 0.011 & 0.014 & 0.014 & 0.007 \\
\hline 15 & $\begin{array}{c}\text { self - } \\
\text { confident }\end{array}$ & 0.012 & 0.014 & 0.014 & 0.008 & patient & 0.011 & 0.009 & 0.011 & 0.003 & intelligent & 0.011 & 0.009 & 0.011 & 0.009 \\
\hline 16 & intelligent & 0.010 & 0.008 & 0.010 & 0.008 & cooperative & 0.007 & 0.006 & 0.007 & 0.002 & righteous & 0.011 & 0.009 & 0.011 & 0.009 \\
\hline 17 & brave & 0.009 & 0.009 & \begin{tabular}{|l|}
0.009 \\
\end{tabular} & 0.007 & 1 & 1 & 1 & 1 & 1 & ambitious & 0.008 & \begin{tabular}{|l|}
0.008 \\
\end{tabular} & 0.008 & 0.002 \\
\hline 18 & 1 & 1 & 1 & 1 & 1 & 1 & 1 & 1 & 1 & 1 & brave & 0.008 & \begin{tabular}{|l|l|} 
\\
\end{tabular} & 0.008 & 0.007 \\
\hline$Q_{j}^{*}$ & & 0.914 & 0.449 & / & / & & 0.838 & 0.358 & / & / & & 0.904 & 0.357 & / & / \\
\hline
\end{tabular}

\section{Discussion}

In terms of JTA, different aspects of the same profession can create different requests for successful job incumbent, which reflects on process of selection. So, it was interesting to see if there are differences between pilots according to the requests of the flight mission, since duties and requests, tasks, rules, nature of mission, requests of pilots and responsibilities, license and school type/level, salary, are not the same for three types of seemingly same profession. It would be expected that military pilots are brave, creative, responsible, obedient, and persistent. Their mission is to defeat an enemy, to live on the edge of knife: to attack different targets in the air, sea or land; to escape enemies attacks from the sea, land or the air; to safely transport people, goods, weapons; to investigate, guard and rescue. These pilots need to be self-reliant and capable of high functioning in stressful, multitasking situation (Boyd et al., 2005). Results of this research show that military pilots have to possess 16 personality traits to be successful and the most important are determined and responsible. Results are consistent with those of Siem and Murray (1994) that military pilots ranked conscientiousness as the most important of 60 personality traits and Lardent's (1991) that military pilots were high on $16 \mathrm{PF}$ Self-assured factor. However, expressive 
traits, like patient and cooperative were low rated and sociable was not of importance at all, which is totally opposite to findings of Galić et al. (2012) that military pilots are a bit extraverted and about average on agreeableness and more social oriented, due to the changing trend in mission, from dog fighting to multi-crew mission.

It would be expected that task nature makes commercial pilots more expressive oriented and assertive and agreeable toward others (other crew members, passengers, colleagues, etc.) and, at the same time to be as relaxed and calm under pressure as their military counterparts. The results confirmed that presumption since the most important traits of successful commercial pilot were cooperative and responsible, among 17 relevant traits. These findings are not in accordance with Lardent's (1991) that civilian pilots scored lower on the Tough-minded, Trusting, Practical, and Relaxed factors. The results are partially consistent with those of Fitzgibbons et al. (2004) that commercial pilots are emotionally stable persons with a low level of anxiety, vulnerability, hostility, impulsiveness, and depression, and at the same time conscientious, a good judges, inclined toward achieving goals, trusting, open, active, and highly self-confident.

In rare investigation of sports pilots, Meško et al. (2013) found that they have higher scores on Agreeableness and Openness scales, less Consciousness and Emotional stability then military pilots. Therefore, it seems that their tasks and duties seems to be easiest, more relaxing, have lower level of pressure, responsibility and more independence during flights, tasks and decision making process, out of all types of pilots. This is in accordance with our results that sport pilots have to possess 18 personality traits to be successful and the most important are sociable and determined. Somehow, implicit expectation about them is that they have to be brave, adventurers with sensation-seeking oriented personalities. The results showed that they indeed are the most gregarious oriented and people directed out of all groups.

All three categories of airplane pilots have opinion that eight traits are not relevant for success in their branch. Those are: emotional, impulsive, tense, permissive, quarrelsome, selfish, modest and stubborn. On the other hand, there are some differences in attitudes toward traits like witty, creative, sociable and obedient. Sport pilots think that witty is important trait for success in their performance. On the other hand, military airplane pilots thought that creativity is important characteristic for successful pilot of their branch. Also military pilots' dispute opinion of other two groups thought that characteristics sociable and obedient are not relevant for them to be successful. Rank of some traits is similar, regardless of the mission type: responsible, determined, careful, practical, efficient. But, in accordance with differences in mission type, different traits have different importance. For example, trait cooperative is very important for successful commercial pilot and sports pilot, but not for successful military pilot. For successful military pilot traits like brave, self - confident, righteous, intelligent have more importance than for the other two categories.

Here we can see the proof how different tasks modify needs and expectations for professional success. Commercial pilots are successful if they are responsible, and hardworking, but also cooperative, since they have to cooperate and communicate with large number of different people: cabin 
crew, passengers, flight control, mechanics, company management, etc. Military airplane pilots are successful if they are determined, responsible and practical, but also brave, self - confident, self - critical, intelligent. Their duty is"to do the right thing", to complete the mission the best possible way no matter the risk. Sports pilots are successful if they are sociable, determined, responsible but also cooperative and witty. Social component is the one which dominates, with fun and friendship, along with common requests.

\section{Conclusion}

So, we might conclude that there are two cores of personality traits of importance for successful airplane pilot: those which presence is relevant for all airplane pilots no matter the branch and those which presence is important for specific mission type. There are qualitative and quantitative differences among specific mission type traits. Model testing showed that in the group of military pilots, traits near the end of the list make difference between successful and unsuccessful candidates, while among sports pilots, traits near the beginning of the list make difference between successful and unsuccessful candidates.

Some ideas for future investigation of this problem can be repetition of the research at a larger sample; comparison of experts, novices and experienced pilots; comparison based on gender, age, type of airplane, differences in cultural expectations of some professions. The significance of the research and its strength rests on the fact that the sample is highly selected and its results might help in the process of selection of novices, or to help pilots in their career transition, to see how differences in type of activity/branch can be followed by different requests, but also to identify factors that may increase the likelihood of human error unique for the group and that way contribute to a safe flight.

\section{References}

Abdullah, L.; Zulkifli, N. 2015. Integration of fuzzy AHP and interval type-2 fuzzy DEMATEL: An application to human resource management, Expert Systems with Applications 42(9): 4397-4409. Available from Internet: <https://ntrs.nasa.gov/api/citations/20040191539/ downloads/20040191539.pdf $>$.

Barrick, M. R.; Mount, M. K. 1991. The Big Five personality dimensions and job performance: A metaanalysis, Personnel Psychology 44(1): 1-26.

Başaran, B. 2012. A critique on the consistency ratios of some selected articles regarding fuzzy AHP and sustainability. In 3 rd International Symposium on Sustainable Development (ISSD'12), Sarajevo. Available from Internet: $<$ https://ssrn.com/abstract=2163459>.

Baykasoğlu, A.; Gölcük, İ.2017. Development of an interval type-2 fuzzy sets based hierarchical MADM model by combining DEMATEL and TOPSIS, Expert Systems with Applications 70: 37-51.

Boyd, J. E.; Patterson, J. C.; Thompson, B. T. 2005. Psychological test profiles of USAF pilots before training vs. type aircraft flown, Aviation, Space, and Environmental Medicine 76: 463-468.

Buckley, J. J. 1985. Fuzzy hierarchical analysis, Fuzzy sets and systems 17(3): 233-247.

Celik, E.; Gul, M.; Aydin, N.; Gumus, A. T.; Guneri, A. F. 2015. A comprehensive review of multi criteria decision making approaches based on interval type-2 fuzzy sets, Knowledge-Based Systems 85: 329-341.

Chen, C. T. 2000. Extensions of the TOPSIS for group decision-making under fuzzy environment, Fuzzy Set Systems 114 (1): 1-9. 
Čokorilo, O. 2008. Risk management implementation in aircraft accident cost analysis. In Proceedings of the 12 th Air Transport Research Society (ATRS) World Conference, 98-102.

Damos, D. L. 1996. Pilot selection batteries: Shortcomings and perspectives, International Journal of Aviation Psychology 6: 199-209.

Dožić, S. 2019. Multi-criteria decision making methods: Application in the aviation industry, Journal of Air Transport Management 79: 1-22.

Fitzgibbons, A.; Davis, D.; Schutte, P.C. 2004. Pilot Personality Profile Using the NEO-PI-R, NASA/ TM-2004-213237, National Aeronautics and Space Administration, Langley Research Center, Hampton, VA.

Galić, Z.; Jerneić, Ž. M.; Kovačić, P. 2012. Do applicants fake their personality questionnaire responses and how successful are their attempts? A case of military pilot cadet selection, International Journal of Selection and Assessment 20(2): 229-241.

Gavade, R. K. 2014. Multi-Criteria Decision Making: An overview of different selection problems and methods, International Journal of Computer Science and Information Technologies 5(4): 5643-5646.

Gibney, R.; Shang, J. 2007. Decision making in academia: a case of the dean selection process, Mathematical and Computer Modelling 46 (7-8): 1030-1040.

Hosseini, M. B.; Tarokh, M. J. 2013.Type-2 fuzzy set extension of DEMATEL method combined with perceptual computing for decision making, Journal of Industrial Engineering International 9(1): 1-10.

Hwang, C. L.; Yoon, K. 1981. Methods for multiple attribute decision making. In Multiple attribute decision making, Springer, Berlin, Heidelberg. 58-191p.
Kahraman, C.; Öztayşi, B.; Sarı, İ. U.; Turanoğlu, E. 2014. Fuzzy analytic hierarchy process with interval type-2 fuzzy sets, Knowledge-Based Systems 59: 48-57.

Kilic, H. S.; Demirci, A. E.; Delen, D. 2020. An integrated decision analysis methodology based on IFDEMATEL and IF-ELECTRE for personnel selection, Decision Support Systems 137: 113360.

King, R. E. 2014. Personality (and Psychopathology) Assessment in the Selection of Pilots, The International Journal of Aviation Psychology 24(1): 61-73.

Kirac1, K.; Akan, E. 2020. Aircraft selection by applying AHP and TOPSIS in interval type-2 fuzzy sets, Journal of Air Transport Management 89: 101924.

Lardent, Jr., C. L. 1991. Pilots who crash: personality constructs underlying accident prone behavior of fighter pilots, Murltivariate Experimental Clinical Research 10: 1-25.

Lathamaheswari, M.; Nagarajan, D.; Kavikumar, J.; Broumi, S. 2020. Triangular interval type-2 fuzzy soft set and its application, Complex \& Intelligent Systems 6: 531-544.

Mendel, J. M. 2007. Computing with words and its relationships with fuzzistics, Information Sciences 177(4): 988-1006.

Meško, M.; Karpljuk, D.; Meško Štok, Z.; Videmšek, M.; Bertoncel, T.; Bertoncelj, A.; Podbregar, I. 2013. Motor Abilities and Psychological Characteristics of Slovene Military Pilots, The International Journal of Aviation Psychology 23(4): 306-318.

Pajić, V.; Andrejić, M.; Kilibarda, M. 2021. Evaluation and selection of KPI in procurement and distribution logistics using SWARA-QFD approach, International Journal for Traffic and Transport Engineering 11(2): 267279. 
Saaty, T. L. 1984. The analytic hierarchy process: Decision making in complex environments. In Quantitative Assessment in Arms Control. Springer, Boston, MA. 285-308p.

Sangaiah, A. K.; Subramaniam, P. R.; Zheng, X. 2015. A combined fuzzy DEMATEL and fuzzy TOPSIS approach for evaluating GSD project outcome factors, Neural Computing and Applications 26(5): 1025-1040.

Sari, I. U.; Kahraman, C. 2015. Interval type-2 fuzzy capital budgeting, International Journal of Fuzzy Systems 17(4): 635-646.

Shappell, S. A.; Detwiler, C.; Holcomb, K.; Hackworth, C.; Boquet, A.; Wiegmann, D. A. 2007. Human error and commercial aviation accidents: An analysis using the human factors analysis and classification system, Human Factors 49(2): 227-242.

Siem, F. M.; Murray, M. W. 1994. Personality factors affecting pilot combat performance: A preliminary investigation, Aviation, Space, and Environmental Medicine 65(5, Sect 2, Suppl): A45-A48.
Stević, Ž.; Pamučar, D.; Vasiljević, M.; Stojić, G.; Korica, S. 2017. Novel integrated multi-criteria model for supplier selection: Case study construction company, Symmetry 9(11): 279.

Sumrit, D.; Anuntavoranich, P. 2013. Using DEMATEL method to analyze the causal relations on technological innovation capability evaluation factors in Thai technology-based firms, International Transaction Journal of Engineering, Management, \& Applied Sciences \& Technologies 4(2): 81-103.

Tadić, S.; Zečević, S.; Krstić, M. 2015. Ranking of logistics system scenarios using combined fuzzy AHPVIKOR model, International Journal for Traffic and Transport Engineering 5(1): 54-63. 